\title{
Path Loss Propagation Evaluation and Modelling based ECC-Model in Lowland Area on $1800 \mathrm{MHz}$
}

\author{
Bengawan Alfaresi ${ }^{1}$, Taufik Barlian ${ }^{2}$, Feby Ardianto ${ }^{3}$, Muhammad Hurairah ${ }^{4}$ \\ 1, 2, 3,4 Department of Electrical Engineering, Universitas Muhammadiyah Palembang, Palembang, Indonesia \\ begawan_alfarezi@um-palembang.ac.id ${ }^{1}$, taufik_barlian@um-palembang.ac.id ${ }^{2}$, feby_ardianto@um- \\ palembang.ac.id ${ }^{3}$, muhammad_hurairah@um-palembang.ac.id ${ }^{4}$
}

\begin{abstract}
Propagation modeling is the most important part of mobile wireless network planning. Wireless network planning requires an accurate calculation of the path, which depends on different environmental conditions. It requires accurate path loss modeling of the characteristics of a specific region. The study aimed to obtain a path loss propagation model by modifying the ECC model and using linear, logarithmic regression in lowland areas. The measurement used drive test method, located in the Jakabaring area that represented the lowland area. This research used four existing path loss models, namely Okumura-Hatta, COST-Hatta, Ericsson Model, and ECC Model. It was found that the Okumura-Hatta model had the largest RMSE value, 34.90, followed by the Ericsson model, 27.07, while the ECC model had the smallest RMSE value, 8.43. The ECC model required to be modified using logarithmic, linear regression to obtain the proposed model. The results of the evaluation showed that the proposed model improved with RMSE 4.93, MAPE 2.71, and MAD 3.91, whereas the values of the existing ECC Model before modification were 8.43 for RMSE, 4.72 for MAPE and 7.09 for MAD. The proposed model provided an accurate prediction of the path loss propagation in a lowland environment. The results of the study can be used for planning engineers to plan, design, and implement the wireless communication networks in lowland area conditions.
\end{abstract}

Keywords- ECC Model, Drive Test, Regression Liner Logartimik, RMSE, MAPE, MAD

\section{INTRODUCTION}

Wireless communication has been experiencing phenomenal growth both in terms of technology and data usage [1]. Internet data usage traffic continues to increase and is expected to increase over the next few years. Demand for service and service delivery has been increasingly heterogeneous and continues to grow, which causes the quality and capacity requirements to become essential needs [2]. Reliable and high-efficiency wireless network planning, therefore, requires accurate path loss planning [4]

Path loss is attenuation caused by radio propagation, namely frequency, the distance between TX and RX, ground operation, and antenna height [5], [6], [7]. The path loss is also induced by losses of free space, refraction, diffraction, reflection, and others [8], [9]. A signal from the transmitter antenna will experience multipath fading to the receiving antenna, which can cause constructive or destructive signals [7]. Path loss is one of the most important factors in link budget analysis or wireless network planning [10].
Propagation modeling is one of the most important aspects of mobile wireless network planning [11], [12], [13]. Various environmental conditions cause a different path loss resulting from radio wave propagation [14], [15 ], [16]. Accurate path loss modeling will be useful for planning, designing and implementation of telecommunications networks and for analyzing network coverage [1], [17], [18]. Several types of propagation are used by network design engineers, namely Okumura, Hatta, Cost231, Cost231-Hatta, ECC model, and Ericsson model [15]. Propagation modeling today is not accurate due to some differences in environment, terrain, and climate conditions [19]. There is no propagation modeling acceptable to all regions [2]. The selection of a propagation model suits in a particular area is not an easy task. It depends on the description of the terrain in a specific area.

Some researchers have researched modeling path loss propagation in various conditions. Pinto et. al. examined path loss determination using linear and cubic regression inside a classic tomato greenhouse [20]. They studied the propagation models for tomatoes greenhouses area, operated in $2.4 \mathrm{GHz}$. This study carried out direct modeling using Cubic Regression. Aljadid [21] researched the modeling of propagation in dense urban areas using $900 \mathrm{MHz}$ frequency. It modified the Hatta model using the Linear Regression method. Nadir and Ahmad developed the propagation model with the modification of the Okumura-Hatta model using Cubic Regression [11]. Majed et. al. investigated path loss models indoor environment at frequencies $4.5 \mathrm{GHz}, 28 \mathrm{GHz}$, and $38 \mathrm{GHz}$. They produced a proposed model and improved it while comparing it with the CI, FI, and ABG models [22].

This research focused on the evaluation of four existing propagation models, namely Okumura-Hatta, Cost231-Hatta, ECC, and Ericsson, as well as on the propagation modeling modification to obtain a modeling adapted to the characteristics of the region and the climate in swampy areas.

\section{METHODS}

The research method consisted of several phases, namely field measurement process using drive test method, simulation of the existing propagation model, propagation model modification, evaluation, and analysis of the proposed model. 


\section{a. Field Measurement process}

Palembang is one of the cities in Indonesia, dominated by swampy areas. The conditions and characteristics of the swampy areas will have different propagation path losses. Terrain and contour conditions affect the characteristics of the propagation path loss.

The measurement process in the field was carried out in lowland areas by measuring the receiving signal level in the area and convert it to the path loss value. Drive test is the measurement of the received strength signal to the EU (User Equipment) of the power emitted by a BTS (Base Transceiver Station) on a moving car to determine the signal's strength and level [23]. Drive testing is usually performed by operators or regulators to check the operator's signal coverage and to determine the quality of the signal received.

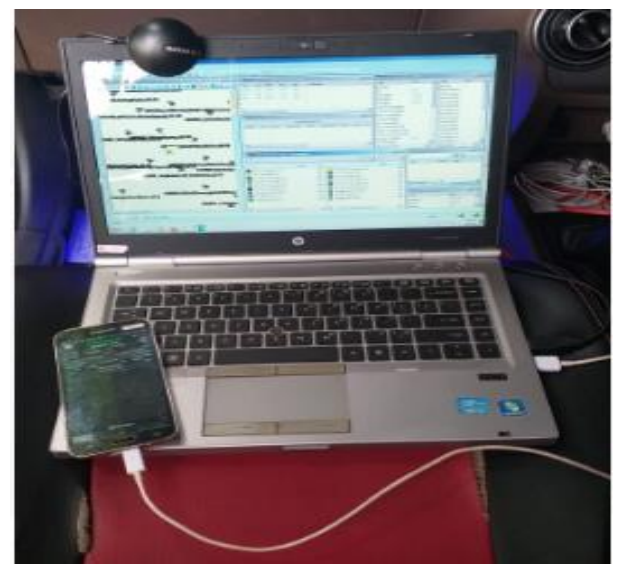

Fig. 1. Drive Test Measuring Equipment

Figure 1 illustrates the drive test measuring equipment. Hardware media consist of HP laptop, Samsung S5 \& cable data, and GPS. The software measurement used was the GENEX Prob. In this study, the sample measurements were carried out using a driving test at the predetermined location and route, according to the objectives of this study.

\section{b. Simulation of the Existing Propagation Model}

This phase determined one of the most realistic existing models to be modified, namely by determining the value of the smallest path loss and the measured path loss results in the four existing model scenarios used. The existing models used were the Okumura-Hatta model, the COST-Hatta model, the ECC model, and the Ericsson model.

\section{Okumura-Hatta Model}

Okumura-Hatta Model is an empirical model based on statistical analysis that combines the Okumura model with the Hatta model. This modeling has an operating frequency range of $1500 \mathrm{MHz}-2000 \mathrm{MHz}$. The formulas for OcumuraHatta are as follows: [3], [15], [24], [25].

Urban:

$L u(d B)=69.55+26.16 \log (f)-13.82 \log (h t e)-$ $a($ hre $)+(44.9-6.55 \log ($ hre $)) \log (d)$

Sub-Urban:

$\operatorname{Lsu}(d B)=\operatorname{Lu}(d B)-2\left(\log \left(\frac{f}{28}\right)\right)^{2}-5.4$
Rural:

$\operatorname{Lru}(d B)=\operatorname{Lu}(d B)-4.78(\log (f))^{2}+18.33 \log (f)-$ 40.98

For small and medium cities:

$a($ hre $)=(1.1 \log (f)-0.7)$ hre $-(1.56 \log (f)-0.8)$

For a big city (fc $\leq 400 \mathrm{MHz}$ )

$a($ hre $)=(8.29 \log (1.54 h r e))^{2}-1.1$

For a big city (fc $\geq 400 \mathrm{MHz}$ )

$a(h r e)=(3.2 \log (11.75 h r e))^{2}-4.97$

where $d$ is the distance $(\mathrm{m}), f$ is the frequency $(\mathrm{GHz})$, hte is the height of the BS antenna (m), hre is the height of the receiver antenna $(\mathrm{m})$, and $a(h r e)$ is the correction factor for cellular station antenna height $(\mathrm{dB})$.

\section{Cost231-Hatta Model}

COST231-Hatta model operates within the 1800-2000 $\mathrm{MHz}$ frequency. This modeling is a combination of COST231 and Hatta models. The COST231 patch can be found in [4], [26], [27].

$$
\begin{aligned}
& L u(d B)=46.3+33.9 \log (f)-13.82 \log (\text { hte })- \\
& a(\text { hre })+(44.9-6.55 \log (h t)) \log (d)+C M
\end{aligned}
$$

For urban area:

$a(h r e)=3.2\left(\left(\log (11.75 \times h r)^{2}\right)-4.97\right.$

For Sub Urban and Rural area:

$a(h r e)=(1.1 \log (f)-0.7) h r-(1.56 \log (f)-0.8)$

$\mathrm{cm}: 0 \mathrm{~dB}$ for medium-size cities and suburban areas

$\mathrm{cm}: 3 \mathrm{~dB}$ for the downtown area

where $d$ is the distance $(\mathrm{m}), f$ is the frequency $(\mathrm{GHz})$, hte is the height of BS antenna (m), and hre is the height of the receiver antenna $(\mathrm{m})$.

\section{ECC Model}

In this model, the path loss is given by the following equation: [28], [29].

$P L=A f s+A b m-G b-G r$

where:

$$
\begin{aligned}
& A f s=92.4+20 \log (d)+20 \log (f) \\
& A b m=20.41+9.83 \log (d)+7.894 \log (f)+ \\
& 9.56[\log (f)]^{2} \\
& G b=\log \left(\frac{h b}{200}\right)\left\{13.958+5.8[\log (d)]^{2}\right. \\
& G r=[42.57+13.7 \log (f)][\log (h r)-0.585]
\end{aligned}
$$

For big cities:

$G r=0.759 h r-1.862$

$d$ is the distance $(\mathrm{km}), f$ is the frequency $(\mathrm{MHz}), h b$ is the height of the BTS, and $h r$ is the height of the receiver antenna (m). 


\section{Ericsson Model}

Ericsson is one of the major vendors in the world. The company has been researching propagation modeling. The Ericsson model of path loss patching is as follows [28]:

$P L=a 0+a 1 \log (d)+a 2 \log (h b)+a 3 \log (h b) \log (d)-$ $3.2(\log (11.75 h))^{2}+g(f)$

$g(f)=44.49\left(\log (f)-4.78(\log (f))^{2}\right.$

where $d$ is the distance between the BTS and users $(\mathrm{km}), h b$ is the height of the BTS $(\mathrm{m}), f$ is the frequency $(\mathrm{GHz})$. The parameters of $a 0, a 1, a 2$, and $a 3$ are adjusted according to specific propagation conditions.

TABLE I. DEFAUlT VALUES OF PARAMETERS IN ERICSSON MODEL

\begin{tabular}{|c|c|c|c|c|}
\hline Environment & $a 0$ & $a 1$ & $a 2$ & $a 3$ \\
\hline Cities & 36.2 & 30.2 & 12 & 0.1 \\
\hline Suburban & 43.20 & 68.93 & 12 & 0.1 \\
\hline Villages & 45.95 & 100.6 & 12 & 0.1 \\
\hline
\end{tabular}

\section{Modification of Propagation Models}

Propagation modeling that has been evaluated and is closest to the conditions in Lowland areas would be modified using logarithmic, linear regression to be used as the $\mathrm{Y}$ value. The linear, logarithmic regression formula is [21]:

$$
Y=a+b x \log (d)
$$

where $a$ is the constant, $b$ is the regression coefficient (slope), and $d$ is the distance as an independent variable. Values $a$ and $b$ may be determined as [8]:

$$
\begin{aligned}
& a=\frac{\left(\sum \Delta \mathrm{L}\right)\left(\sum(\log d)^{2}\right)-\left(\sum \log d\right)\left(\sum \Delta \mathrm{L} * \log d\right)}{n\left(\sum(\log d)^{2}\right)-\left(\sum \log d\right)^{2}} \\
& b=\frac{n\left(\sum \Delta \mathrm{L} * \log d\right)-\left(\sum \log d\right)\left(\sum \Delta \mathrm{L}\right)}{n\left(\sum(\log d)^{2}\right)-\left(\sum \log d\right)^{2}}
\end{aligned}
$$

Where $\Delta L$ is the difference between the path loss value from the drive test measurement and the modeling.

\section{Evaluation of the Existing Propagation Model}

This study adopted three index evaluation parameters to evaluate the accuracy of propagation modeling, namely: Mean Absolute Percentage Error (MAPE), Root Mean Square Error (RMSE), and Mean Absolute Deviation (MAD).

MAPE is the absolute value of the percentage error data against the mean value, or it can be formulated as [30]:

$M A P E=\frac{\sum\left(\frac{P L_{-} \text {model }-P L \_ \text {meas }}{\text { Actual }}\right) \times 100}{n}$

RMSE is the sum of the error squares or the difference between the actual value and the predicted value, then divides the amount by the amount of time forecast data and then draws its roots, or can be formulated as [23], [31].

$R M S E=\sqrt{\frac{\sum\left(P L_{-} \text {meas }-P L_{-} \text {model }\right)^{2}}{n}}$
MAD is the absolute value of the data deviation from the mean, or it can be formulated as: [30]

$M A D=\sum \frac{\left(P L_{-} \text {meas }-P L \_ \text {model }\right)}{n}$

where:

$n=$ the number of sample data.

$P L \_m e a s=$ the values obtained by measuring the device.

$P L \_$model $=$the value obtained using the equation.

\section{RESUlt AND DisCUSSION}

This chapter analyzes the results of the modification process of the existing model channel and the evaluation of the resulting model.

a. The Comparison Analysis of Existing Path Loss Models

The four propagation models used in this study were Okumura-Hatta, Cost231-Hatta, Ericsson Model, and ECC Model. The simulation used the type of suburban area, adjusted to the area condition measured in the lowland Jakabaring area. The frequency used in this research was $1800 \mathrm{MHz}$, and the transmitter was a $4 \mathrm{G}$ network. The results of the comparison of simulation path loss can be seen below.

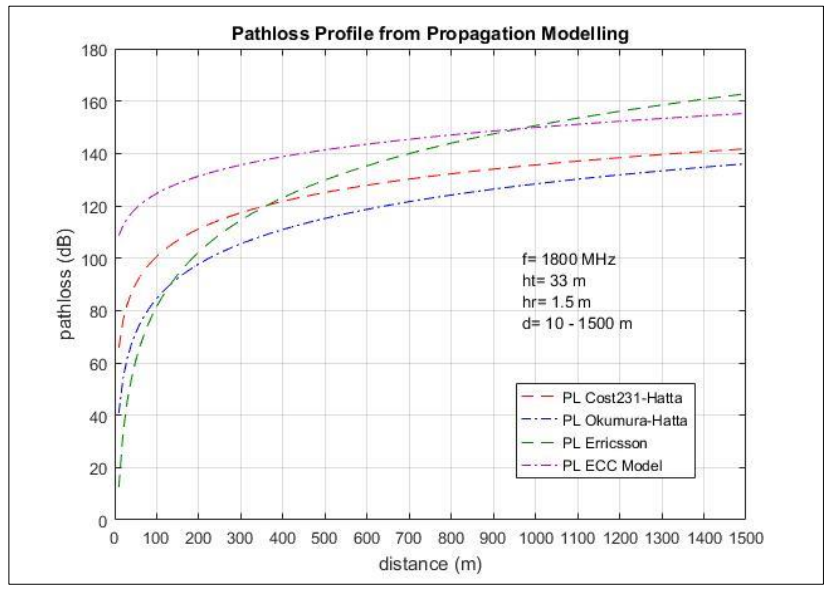

Fig. 2. Comparison of Path Loss in Existing Propagation Model

Figure 2 shows the comparative results of the path loss of the four existing models. The path loss generated by the ECC model had a greater value compared to the other three models, while the Okumura-Hatta had the smallest value. Conversely, the Ericsson had the greatest increase slope in path loss compared to others. Distances $<150 \mathrm{~m}$ contributed to smaller path loss values, while distances $>900 \mathrm{~m}$ provided higher path loss values.

b. Comparison of Field Measurement with Existing Models Simulation Results

Measurements were made using the drive test method in a predetermined area, based on the characteristics of the swamp area. The area selected was the Jakabaring area, in Palembang city, where almost all areas are swampy. 


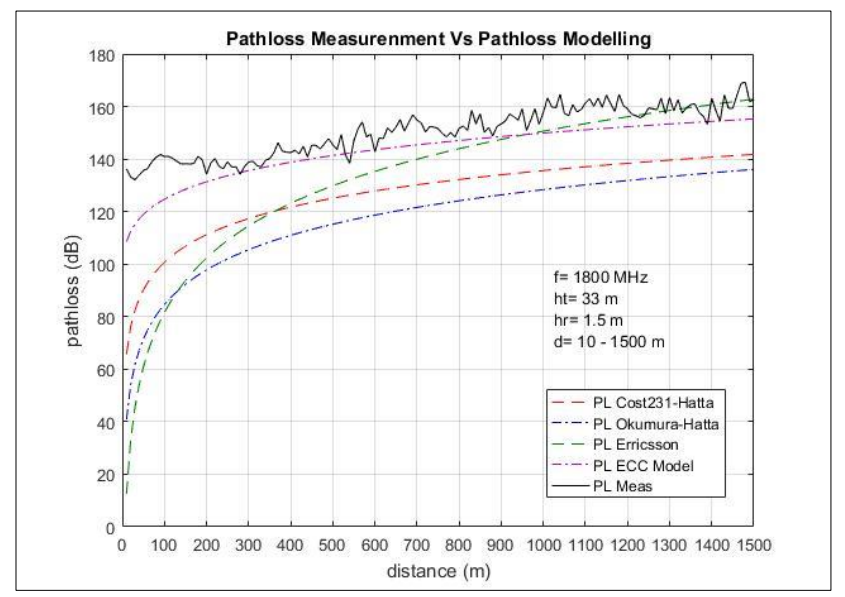

Fig. 3. Comparison of Path Loss in Field Measurement with Existing Propagation Model

Figure 3 shows the results of the test drive measurements that the path loss value is directly proportional to the distance between the BTS and users. At the distance of 0-1500 m path loss measurements, it resulted in a higher value. The ECC model had the closest trend value to the measurement results at a distance of $<1000 \mathrm{~m}$, whereas the Ericsson model had the most detailed path loss value at a distance of $>1000 \mathrm{~m}$.

This research used RMSE, MAPE, and MAD to obtaining the value of delta path loss accumulation. Evaluation of propagation modeling was completed using equations (1820). The results of the calculation are as follows. Table 2 presents the evaluation paremeter values on the four existing models

TABle II. EVAluation Paremeter VAlues ON The EXISTING MODELS

\begin{tabular}{|c|c|c|c|c|}
\hline \multirow{2}{*}{ Model } & \multicolumn{4}{|c|}{ Jakabaring (Palembang) } \\
\cline { 2 - 5 } & Okumura-Hatta & Cost-Hatta & Erricsson & ECC Model \\
\hline RMSE & 24.98 & 34.90 & 27.07 & 8.43 \\
\hline MAPE & 15.88 & 22.30 & 12.30 & 4.72 \\
\hline MAD & 23.63 & 33.06 & 17.52 & 7.09 \\
\hline
\end{tabular}

Table 2 shows that the COST-Hatta model has the highest RMSE value of 34.90 , followed by the Ericsson model (27.07) and the Okumura-Hatta model (27.07), while the ECC model has the smallest RMSE value of 8.43. It means that the modeling closest to the Lowland condition is the ECC model. The smallest value compared to other models was 8.43 , the RMSE. The MAPE value of the ECC was 4.72, and the MAD value was 7.09. It indicated that the deviation of the driving test in the Lowland area using the ECC model provided the smallest deviation compared to the other three models. Thus, the ECC model became the basis for new modeling modifications.

c. Modification of ECC Model Using Logarithmic Linearity Regression

The ECC formula model is as in (10-13), where these study measurements were made in sub-urban or mediumurban areas, specifically in Low Land areas, using equations
(14). Logarithmic, linear regression formula used equations (21-22) that generate:

$$
\begin{aligned}
& \mathrm{a}=8.503 \\
& \mathrm{~b}=-0.00199
\end{aligned}
$$

The full ECC model formula is:

$P L=92.4+20 \log (d)+20 \log (f)+20.41+$ $9.83 \log (d)+7.894 \log (f)+9.56[\log (f)]^{2}-$ $\log \left(\frac{h b}{200}\right)\left\{13.958+5.8[\log (d)]^{2}-[42.57+\right.$ $13.7 \log (f)][\log (h r)-0.585]+(a+b \log (d))$

Values $a$ and $b$ are substituted into equation (24), then:

$P L=92.4+20 \log (d)+20 \log (f)+20.41+$ $9.83 \log (d)+7.894 \log (f)+9.56[\log (f)]^{2}-$ $\log \left(\frac{h b}{200}\right)\left\{13.958+5.8[\log (d)]^{2}-[42.57+\right.$ $13.7 \log (f)][\log (h r)-0.585]+(8.503-0.00199 \log d)$

Thus, the proposed model of path loss for is:

$P L=38.15+29.83 \log (d)+20 \log (f)+7.894 \log (f)+$ $9.56[\log (f)]^{2}-\log \left(\frac{h b}{200}\right)\left\{13.958+5.8[\log (d)]^{2}-\right.$ $[42.57+13.7 \log (f)][\log (h r)-0.585]$

d. Comparison of Proposed Models with Existing ECC models.

Results formulation of the proposed model is simulated using MatLab to be compared to the ECC Model. The two simulation results are compared to the trend of the measurement results by Drive Test.

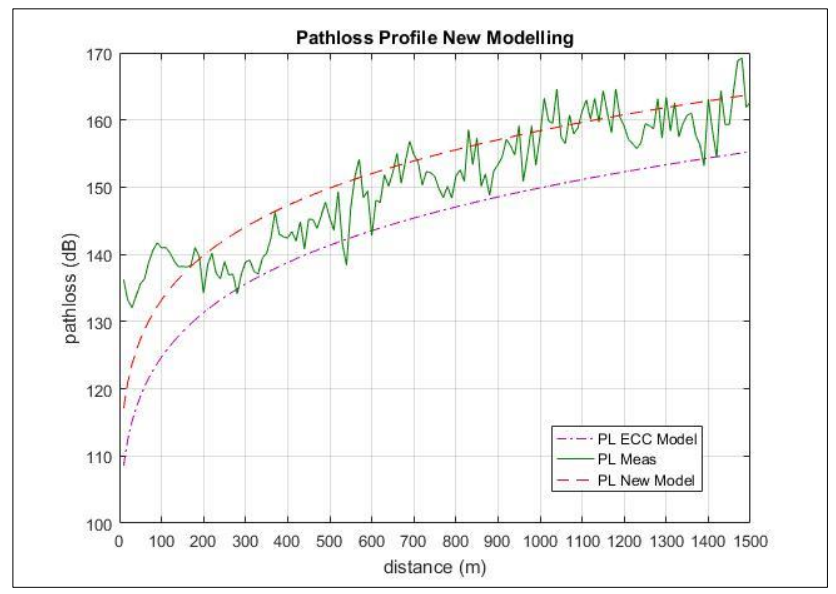

Fig. 4. Comparison of path loss in existing propagation models

Based on the simulation results shown in Figure 4, the path loss generated by the proposed model has a higher value than the path loss in the previous ECC model and the distance value is constant. The value of the proposed model was closer to the measurement results than the previous ECC model. The values of RMSE, MAPE, and MAD were compared to obtain the values of delta path loss accumulation between measurement results and path loss models. The results of the calculation are shown in Table 3 . 
TABLE III.

THE COMPARISON OF EVALUATION PARAMETERS BETWEEN ECC AND PROPOSED MODELS

\begin{tabular}{|c|c|c|}
\hline \multirow{2}{*}{ Area } & \multicolumn{2}{|c|}{ Jakabaring (Palembang) } \\
\cline { 2 - 3 } & ECC Model & Proposed Model \\
\hline RMSE & 8.43 & 4.93 \\
\hline MAPE & 4.72 & 2.71 \\
\hline MAD & 7.09 & 3.97 \\
\hline
\end{tabular}

Table 3 shows that the RMSE value in the ECC New Model has a lower value compared to the previous ECC Model, which is 4.93. The values of MAPE and MAD in the ECC New Model are 2.71 and 3.97, showing that the values in the ECC Model are smaller. Thus, the three parameters show that the use of the ECC New Model is closer to driving test results in the Lowland area field.

\section{CONCLUSION}

Research results show that the Sub-Urban conditions, the path loss generated by the ECC propagation model, have the highest path loss value compared to the Okumura-Hatta, Cost231-Hatta, and Ericsson models. Propagation modeling that most closely matches the value of the measurement results is the ECC model with the values of RMSE 8.43, MAPE 4.72, and MAD 7.09. The results of the modification of New using logarithmic, linear regression provide increased accuracy of measurements, namely RMSE 4.93, MAPE 2.71, and MAD 3.91, which means that the modified ECC New Model is an accurate model that can be used in the Lowland area.

\section{REFERENCES}

[1] O. F. Oseni, S. I. Popoola, R. O. Abolade, and O. A. Adegbola, "Comparative Analysis of Received Signal Strength Prediction Models for Radio Network Planning of GSM $900 \mathrm{MHz}$ in Ilorin, Nigeria,” Int. J. Innov. Technol. Explor. Eng., no. 3, pp. 2278-3075, 2014.

[2] B. O. Akinwole and C. Esobinenwu, "Adjustment of Cost 231 Hata Path Model for Cellular Transmission in Rivers State," IOSR J. Electr. Electron. Eng., vol. 6, no. 5, pp. 16-23, 2013, doi: $10.9790 / 1676-0651623$.

[3] C. Study and N. Elfadil, "Impact of Using Modified Open Area Okumura-Hata Propagation Model in Determination of Path-loss: Malaysia as Case Study,” Int. J. Mod. Eng. Res., vol. 7, no. 5, pp. $1-6,2017$

[4] C. Emeruwa and P. . Iwuji, "Determination Of A Pathloss Model For Long Term Evolution ( Lte ) In Yenagoa,” Int. J. Eng. Sci., vol. 7, no. 10, pp. 38-44, 2018, doi: 10.9790/1813-0710033844.

[5] C.A.D Pahalson, N.S. Tarkaa and G.A.Igwue, "Method for Analysis of System Coverage and Capacity for a GSM Based Cellular Network,” Int. J. Mod. Trends Sci. Technol., vol. 5, no. August, pp. 74-87, 2019.

[6] O. O. Shoewu, L. I. Oborkhale, N. O. Salau, and O. O. Bashorun, "Analysis of Outdoor Path Loss Measurements for Triple Frequency Spectrum in Lagos State," Pacific J. Sci. Technol., vol. 18, no. 2, pp. 144-154, 2017.

[7] J. Of and A. In, "Pathloss Modelling of less dense urban area in Lagos State using Lee Model,” J. Adv. Eng. Technol., vol. 4, no. 4, pp. 1-4, 2017, doi: 10.15297/JAET.V4I4.01.

[8] A. O. A, T. O. A, M. O. S, and A. J. A, "Experimental Study of Variation of Path Loss with Respect to Heights at GSM Frequency Band,” Int. J. Sci. Res. Sci. Eng. Technol., vol. 3, no. 3, pp. 347351,2016
[9] Alor MO, "Efficient Pathloss Model for determining Mobile Radio Link Design,” Int. J. Sci. Res. Sci. Eng. Technol., vol. 3, no. 3, pp. 270-276, 2015.

[10] O. I. Adu, F. E. Idachaba, and A. A. Alatishe, "Refarming $1800 \mathrm{MHz}$ GSM spectrum to LTE: He effects on coverage based on pathloss estimation,” Lect. Notes Eng. Comput. Sci., vol. 1, pp. 673-676, 2014.

[11] Z. Nadir and M. I. Ahmad, "Pathloss determination using OkumuraHata model and cubic regression for missing data for Oman," in Proceedings of the International MultiConference of Engineers and Computer Scientists 2010, IMECS 2010, 2010, vol. II, no. 1, pp. 804-807.

[12] L. A. Akinyemi, O. O. Shoewu, N. T. Makanjuola, and A. A. Ajasa, "Path Loss Models Analysis for Rural-Urban Vegetational Cases in Lagos Environs," Comput. Inf. Syst. Dev. Informatics Allied Res. J., vol. 5, no. 4, pp. 47-60, 2014.

[13] D. C. Abraham, "A Generalized Regression Neural Network Model for Path Loss Prediction at $900 \mathrm{MHz}$ for Jos City , Nigeria," Am. J. Eng. Res., vol. 5, no. 6, pp. 1-7, 2016.

[14] M. Yang and W. Shi, "A linear least square method of propagation model tuning for 3G radio network planning," in Proceedings - 4th International Conference on Natural Computation, ICNC 2008, 2008, vol. 5, pp. 150-154, doi: 10.1109/ICNC.2008.188.

[15] K. O. Kadiri and O. A. Somoye, "Computer Simulation of Path Loss Characterization of a Wireless Propagation Model in Kwara State, Nigeria,” Int. J. Comput. Inf. Technol., vol. 3, no. 3, pp. 610-615, 2014.

[16] M. N. Islam, B. J. J. Kim, P. Henry, and E. Rozner, "A wireless channel sounding system for rapid propagation measurements," in IEEE International Conference on Communications, 2013, pp. 5720-5725, doi: 10.1109/ICC.2013.6655507.

[17] Deussom Djomadji Eric Michel, "New Approach for Determination of Propagation Model Adapted To an Environment Based On Genetic Algorithms: Application to the City Of Yaoundé, Cameroon," IOSR J. Electr. Electron. Eng., vol. 10, no. 1, pp. 4859, 2015, doi: 10.9790/1676-10134859.

[18] O. Shoewu and A. Adedipe, "Investigation of radio waves propagation models in Nigerian rural and sub-urban areas," Am. J. Sci. Ind. Res., vol. 1, no. 2, pp. 227-232, 2010, doi: 10.5251/ajsir.2010.1.2.227.232

[19] K. A. Adeniji, O. F. Ikpeze, T. O. Ejidokun, and K. Suleiman, "Analysis of Propagation Models for Base Station Antenna: A Case Study of Ado-Ekiti , Nigeria," ABUAD J. Eng. Res. Dev., vol. 1, no. 1, pp. 124-129, 2017.

[20] D. Cama-Pinto, M. Damas, J. A. Holgado-Terriza, F. Gómez-Mula, and A. Cama-Pinto, "Path loss determination using linear and cubic regression inside a classic tomato greenhouse," Int. J. Environ. Res. Public Health, vol. 16, no. 10, pp. 1-15, 2019, doi: 10.3390/ijerph16101744.

[21] E. R. Abboud, "Propagation Model for the $900 \mathrm{MHz}$ Almadar Aljadid Mobile Network at Tripoli Area Using Linear Regression Method," in The Proceedings of Second International Conference on Electrical and Electronics Engineering, Clean Energy and Green Computing, 2015, pp. 5-11.

[22] M. B. Majed, T. A. Rahman, O. A. Aziz, M. N. Hindia, and E. Hanafi, "Channel characterization and path loss modeling in indoor environment at $4.5,28$, and $38 \mathrm{GHz}$ for $5 \mathrm{G}$ cellular networks," Int. J. Antennas Propag., vol. 2018, 2018, doi: 10.1155/2018/9142367.

[23] S. O. Olatinwo, L. I. Oborkhale, and O. O. Shoewu, "Wireless Network Modelling and Analysis using Path Loss Models," Pacific J. Sci. Technol., vol. 18, no. 2, pp. 132-143, 2017.

[24] O. Shoewu, S. O. Olatinwo, and D. D. Olatinwo, "Comparative Analysis of Pathloss in Metropolitan Domain in Nigeria using Okumura-Hata Model,” Eur. J. Sci. Res., vol. 141, no. 1, pp. 5-15, 2016.

[25] O. P. Omolaye, G. A. Igwue, and G. A. Akpakwu, "OKUMURAHATA: A PERFECT MODEL FOR DRIVING ROUTE UHF INVESTIGATION,” Am. J. Eng. Res. ( AJER ), vol. 4, no. 9, pp. 139-147, 2015.

[26] P. Maina, G. Chandra Manna, and N. Sahayam, "Validation Study of Path Loss Models on Wimax At 2.6 Ghz Frequency Band in 
Suburban Environment for Cell Size Planning," Int. J. NextGeneration Networks, vol. 6, no. 2, pp. 17-29, 2014, doi: 10.5121/ijngn.2014.6202.

[27] A. Chinedu and O. A. Christian, "An Exponent-Based Propagation Path Loss Model for Wireless System Networks at Vehicular Speed,” Am. J. Eng. Res., vol. 5, no. 1, pp. 125-136, 2016.

[28] O. Shoewu, L. A. Akinyemi, and L. Oborkhale, "Modelling Path Loss in Mobile Communication 4G Network System for Dryland and Wetland Terrains," in Southern Africa Telecommunication Networks and Applications Conference (SATNAC), 2019, pp. 4449.
[29] N. A. Ann and E. K. Chukwunonyerem, "A study of propagation path-loss models,” Am. J. Eng. Res., vol. 4, no. 11, pp. 171-175, 2015.

[30] U. Khair, H. Fahmi, S. Al Hakim, and R. Rahim, "Forecasting Error Calculation with Mean Absolute Deviation and Mean Absolute Percentage Error," J. Phys. Conf. Ser., vol. 930, no. 1, 2017, doi: $10.1088 / 1742-6596 / 930 / 1 / 012002$.

[31] S. O, S. N. O, O. A. O, and O. L. I, "Path Loss Measurement and Modeling for Lagos State G.S.M Environments," Rev. Comput. Eng. Res., vol. 3, no. 4, pp. 69-81, 2016, doi: 10.18488/journal.76/2016.3.4/76.4.69.81. 